B. A. Bilby FRS*

INTODUCTION

here are three important processes whereby a condensed phase can be seprated into two parts. Cracking, in which rows of atoms or molecules are whed apart normal to their centres of mass; sliding off, in which finit wows of them slide over one another until they ultimately paxt company; and the removal of individual atoms, as in vacancy migration or electromomical attack. These processes, and, in crystals, those of deformation miming and martensitic transformation also, interact on a microscale during the manufacture, assembly and use of materials to produce each
uther. Inhomogeneities of material and structure may lead to cracking and oids; cracking is relaxed or blunted by local sliding while sliding an wiming themselves can cause cracking. So our engineering structures cherally contain many small cracks and voids, as well as inhomogeneities n material and structure which readily generate them under loads. I Practure we are mostly interested in the conditions under which these smal Iscontinuitios can grow and propagate as macroscopic cracks. For this propagition to proceed, two conditions must be satisfied. It is necessary What the decrease of total energy (the elastic energy of the body plus the petential energy of the loading system) be at least equal. to tho energy aqured to drive this separation process; and it is necessary that some Wysical mechanism can take place permitting this separation to occur. tales. We may look at a catastrophic failure occurring in a massive ches. We may look at a catastrophic fadiure occuring in a massive tracture; at in specimen undergoing a facture toughnoss test; at a sma chion hear the tip of a langer crack where theop or at slip occurring on rowth or slow extension durlng latigue or creep; or at slip occuring whever, these two principles govern the extension process.

the engineer must design and build structures and keep them safely in ar entical tests to character wrvice. So there arises a continual need for practical tests to cha - the properties of materials. As understanding of these properties woro fistory of fracture and fracture mechanics is yet another example of how heory and practice interact to their mutual advantage. At the present Wme, when science is a little unfashionable, it is well to remember that comot go against Nature and that our progress will be faster if we coam a little to understand her ways. 
FRACTURE CRITERIA

In a linear elastic material the singular field $p_{i j}$ near the tip of a sharp crack is characterized by the stress intensity factors $K_{1}, K_{2}, K_{3}$ and has

$$
p_{i j}=(2 \pi r)^{-1 / 2} k_{s} f_{s i j}
$$

where the $\mathfrak{f}_{\mathrm{S} i \mathrm{j}}$ depend on $\theta$. If the advance of the crack is governed by the stress field in this region, then we can determine by a test, for example in mode $I$, the critical value $K_{1 c}$ at which the crack will advance catastrophically. Then, if the service environment and other conditions are similar to those of the test, a cracked structure is secured against catastrophic failure until the $K_{1}$ for some crack in it reaches $K_{1}$. This is the basis of linear elastic fracture mechanics. In the test, the departures from linear elasticity at the crack tip are carefully controlled. can difficultes to small scale yielding. However, are whe generally accompanied by considerable departures from linearity, and when we try to make small scale tests on tough materials. The problems are compounded by the facts that fractures in structures occur under combined stresses and by the necessity of making proper allowance for chemical
reactions, temperature, and varying stress.

For a sharp crack in an ideally brittle elastic naterial the critical $K$ criterion embraces both of the fundamental conditions for fracture. The model by the infinite' the existence of of preaking. Althouh the point much more cesses of this kind are courring have to remember that separation prothus important to model them and which they occur is affected by the rate at This is because whether such influence the nature of the whole macroscopic

The energy condition we now formulate in terms of the energy release rate or erack extension force $G$, introduced in 1948 by Irwin [2] and shown by him in $1957[3,4]$ to be determined by $K$. Griffith's energy condition. $[5,6]$ may then be written $G=2 \gamma$, where $\gamma$ is an effective surface energy for fracture; altematively we have (in mode $I$ ) $G=G_{1 C}=K_{1}^{2} / 2 M$, where $G_{1 c}$ is a critical value of $G$ and $M$ is an elastic modulus [7]. From thi point of view $K_{3 c}$ is an indirect way of describing the effective surface energy for fracture. In 1960, G was expressed as a path-independent

integral [8], and in 1968 a number of authors [1,9-11] independently gave related expressions for $\mathrm{G}$, one of which is now widely known as the integral. The generalisation to the dynamic case was also considexed at this time [12], and it was shown [1, 12] that the theory of the crack extension force followed naturally from the general theory of forces on elastic singularities developed in 1951 using the energy-momention tensor

Many computations and experiments have been devoted recently to the examination of $J$ and quantities related to it as candidates for fracture

criteria in post yield fracture mechanics. This work is not always easy to follow because of variations in the terminology and interpretation of Ufferent authors. Moreover, the confusion is worse confounded by the ance of similar symbols for the integrals themselves (which are mathematical chites in their own right, and which can be calculated as numbers withant any interpretation if desired), and other quantities. These latter fuantities are derived from the experimentally determined load-deflection aring cracks of various lengths, or sometimes, *h the help of approximate theories, by other experimental methods. hey, and the integrals themselves, are also calculated theoretically che computers. the specimens were non-linear elastic these quantities (as well as the mtegrals themselves) would be crack extension forces, but in the usual to [2 whall now try to dis

\section{WUDAMENTAL INTEGRALS}

on the linear or non-linear elastic body the quantity

$$
F_{l}=\int_{S} P_{\ell j} d S_{j}
$$

(3) such that $-F_{\ell} \delta \xi_{\ell}$ is the free energy change when all singularities inside closed surface $S$ drawn in the body are displaced by $\delta \xi_{\ell}$ [13] (we limit tero

$$
P_{\ell j}=W \delta_{\ell j}-P_{i j} u_{i, \ell}
$$

the energy-momentun tensor of the elastic ficld for which the stresses ij are given by $\partial W / \partial u_{i, j}$ and $+W\left(u_{i}, u_{i}, j, x_{i}\right)$ is the strain energy thes a to field quantices, but also explicitly on $X_{i}$, the initial coordinates. (We use a metation which makes (2) valid for the finite deformation of a non-linear bastic material; $p_{i j}$ is the (unsymmetrical) nominal or Boussinesq or and piola-kirchijo the undeformed body. $-W$ is, are the field ment can readily be extended if need be to a material of grade $n[19,20]$ usint can readily be extended if need be to

$$
\frac{\partial Q_{\ell j}}{\partial x_{j}}=\left(\frac{\partial W}{\partial x_{\ell}}\right)_{\exp }
$$

were "exp" denotes the explicit derivative, with $u_{i}, u_{i}, j$ and $x, j \neq \ell_{\text {, }}$ held constant. Putting $\ell=1$, regarding the crack ejther as a distribution t dislocations [1] or as a singularity in its own right [15], and letting $d s_{j}=n_{j} d s$ for $j=1,2$, we get for the crack extension force,

$$
F_{1}=\int_{\Gamma}\left(W \delta_{i . j}-p_{i, j} u_{i, j}\right) n_{j} d s
$$


The divergence of the integrand vanishes if $\left(\partial W / \partial x_{1}\right) \exp =0$; that is, if the material is homogeneous in the direction $x_{1}$ of the crack extension. However, it may be inhomogeneous in the $x_{2}$ direction; for example, the crack might lie between two different media. The integral $J[9]$ is
same form as (5), but $W$ may be replaced by $W^{\prime}$, the density of stress working

$$
W^{\prime}\left(x_{m}, t\right)=\int_{0}^{t} p_{i j}\left(x_{m}, t^{\prime}\right)\left\{\partial u_{i, j}\left(x_{m}, t^{\prime}\right) / \partial t^{\prime}\right\} d t t^{\prime}
$$

where $t$ is a parameter denoting the progress of the deformation. The derivation of $F_{1}$ and the proof of its path-dependence involves the assumpindependent of $\Gamma$ in linear and non-linear elasticity. Deformation plasticity, provided there is no unloading, can be regarded as a kind of non-1inear elasticity. Thus, if the same strains and displacements are used in both $J$ and $F_{1}$, they are again identical and path-independent. In a region of plasticity modelled by the incremental theory, J may be evalwated with du interpreted as the total shape displacement giving the shape change of the solid; that is, $d u_{i}=d u_{i}^{+}+d u_{i}$, where $E$ and $P$ denote the elastic and plastic contributions. No general proof that it is then path-independent has been given, although, as discussed at ICF 3 [22], it may be approximately so [23]. It is clear that the arguments leading to the path-independence of $\mathrm{F}_{1}$ aepend on the existence of the function $W$. Now, if in the actual loading the density of stress working is independen of the stress-strain path, $W$ is a function only of the current state and not of the strain history. Thus $W$ can be used for $W$ in $F_{1}$; then if $u$ is the total shape displacement, $J \delta$ and $\mathrm{F}_{1}$ are the same and are independen of $\Gamma$, for we cannot tell that the field quantities were not derived from density function [24]. A steadily moving plastic-elastic crack is an example of this kind [25]. The matter has been discussed recently in term of the DBCS model $[26,27]$. It is emphasized that, in general, $J$ is path independent in any situation where $W$ is independent of the stress-strain path by which the current state is reached [27]. It will be evident that by using various combinations of the elastic, plastic (or total) strain and displacements appearing in the two terms of the integrands a considerable number of integrals resembling $J$ and $F_{1}$ can be obtained. It would be helpful, when these are evaluated numerically, if the quantities being evaluated were very clearly defined. Studies of the path-dependence
of $I$ in incremental plasticity are continuing $[14,28,29]$.

If plastic flow has occurred at the crack tip, the integral $F_{\ell}$ gives the 1 plant force on the crack tip and on all the dislocations inside $S$ $[13,26]$, but it is defined only for paths in the elastic region. However, $[13,26]$, but $\mathrm{O}$ may be derived $[22,30]$ which reduces to $F_{2}$ in the elastic region and which can be taken through a continuous distribution of dislocrack tip plasticity (and any micro-cracking there). This integral $Q_{\ell}$ was given at 1 CF 3 and is [22]

$$
Q_{\ell}=\int_{S}\left(W_{\ell, j}-p_{i j} \beta_{\ell i}^{E}\right) d S_{j}
$$

where $W$ is the elastic energy density and $B_{\ell i}^{E}$ the elastic distortion tensor giving the spatial increments of elastic displacement $d u_{i}=d x_{\ell} \beta_{l i}$ in $a$ continuous distribution of dislocations (the elastic displacement $u_{i}$ does not exist $[31,32,33])$. Q Q reduces to zero when shrunk on to the crack
- 2 ain [34]. As discussed at ICF3 [22], it would not be surprising if a malistic nuastic zone were in neutral equilibrium, jn the sense that any energy melaased by crack advance is absorbed by plastic work. This may be show to be so for the quasi-static DBCS model $[1,35,36]$, for the dynamic who model [15, 37], and, more generally, [38], for elastic-plastic matseo also [39] for further discussion. These questions raise problems wout the use of quantities like $F_{l}$ and $J$ for the characterization of arack extension [22]. The interpretation of $F_{1}$ shows that $F_{1} \delta \xi$ is the erexgy released when the crack tip and all dislocations representing the pusticity are displaced in the $x_{1}$ direction for $\delta \xi$. This is not (neces aarily an equilibrium displacement of the crack and its plasticity, but the significance of this energy release, and how much of it is mopped up by plastic work in an actual movement of the crack, are not clear. Atte che has again been focussed on the matter by recent numerical work rate fo 41] confirming the result $[25,38]$ that there is no energy release rate arowing cxack in plastic-elastic material. If $-\Delta W$ is the work or th that loading the initially stressed segments of crack face it is suggested chat a crack tip energy release rate $G \Delta=\Delta W / \Delta$ a calculated over a finite $a \rightarrow 0)$.

Discegarding heat fluxes, we can write for an imposed small extension $\Delta a$ of the crack tip,

$$
-\Delta E_{P O T}=\Delta E_{E L}+\Delta W+G \Delta a+O\left(\Delta a^{2}\right)
$$

ferc - aber is the work done by the loading system, $\triangle E_{E L}$ the increase in rod elastic eneros sw the work dissipated in plastic flow and GAa the energy released at the crack tip. In linear and non-linear elasticity, when $\Delta w=0$, i.t is the essential property of the integrals $F_{1}$ and $J a{ }^{\prime} \Delta a$, they give $G$ dixectly. For the fracture conditit where $2 \gamma$ is the effective surface energy fhows that the plastic elastic - 0 when plastic flow is allowed really shows that the make a more antinum models considered are tracture process allowing for rate effects, realistic representation of thacture zone. At the mitero-cracking and mochanical jno of the plastic work into the fracture mplest lovel, we sit process; this is the extenanergy, recognising it as partan 2ion. [4]. In a semi quanis idea As has been noted [22], its developments 0 used to develop this $10,45 \ldots 47]$ show some of the qualitative co include rato stable growth and the transition to past fracture.

Crom any numerical solution for the plastic-elastic crack, we can calculate rom any numerical solution for $J$ and the increment $\Delta E_{\text {pOT }}+\Delta E_{B L}+\Delta W$ not anly the also by suitable integration cher the developing field, the quantities +EPOT, EEL and $w$ as we load up we can then find the derivative

(iip 14] that these quantities are not the same. This we should indeed expect. or, as in the corresponding experimental procedure when we load up speci gens with cracks of increasing length $[48-50]$, we are not dealing with perfect differentials. The states obtained after loading a specinen of 
crack length a and allowing it to extend to a $+\Delta a$ or alternatively loading a specimen of crack length a $+\Delta$ a are different $[21,51]$. It is not 作 the cracks of lengths $a$ and $a+\Delta a$, is $-J \Delta a$, nor is the connection with crack extension at all straightforward [24]. It is thus a matter for experimental study whether these or related methods [52 - 54] will yield a satisfactory characterisation of the onset of fracture.

\section{THE CRITICAL DISPLACEMENT CRITERION}

An interesting development using a critical displacement criterion for fracture began with the appearance of the BCS fracture theory $[55,56]$, which uses a highly simplifjed model of the crack tip plasticity consisting of a linear axray of dislocations. A similar model to remove the elast crack tip singularity and represent the plasticity was used by Dugdale [57]; a closely related (though not quite equivalent) procedure for eliminating the crack tip singularity is central to Barenblatt's work [58]. The procedure has also been used by Vitvitskii and Leonov (see [59]); similar idea was employed by Prandt 160$]$. The DBCS model has been elaborated in various ways and very widely applied to discuss many aspects of fracture [61 - 89]; recent reviews have discussed some of these developments $[1,22,51]$. An aspect which is currently receiving increasing attention is the BS (Bilby-Swinden [70]) model in which two (or more) dislocation arrays inclined to the crack are used in an attempt to make a slightly more realistic representation of the plasticity [42, 88 - 91].

The DBCS model has also been used in discussions of the COD concept in post-yield fracture mechanics $[92-95]$. There has been a considerabl development of this criterion on the engineering side, but, like its thater for further elucidation and debate.

Nevertheless the use of the criterion in the BCS theory has been very useful in providing a two-parameter model fo the energy expended in the Eracture process, and an interpolation between the Griffith theory (or or plastic collapse. If $\phi_{c}$ is the critical displacement at the crack tip

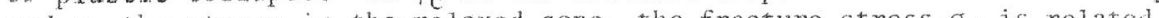
and $\sigma_{1}$ the stress in the relaxed zone, $[65,66]$

$$
\sigma_{f^{\prime}} / \sigma_{1}=(2 / \pi) \cos ^{-1}\left\{\exp \left(-c^{*} / \pi c\right)\right\}
$$

where $c^{*}=M \phi_{c} / 4 \sigma_{1}, M$ being an elastic modulus. The condition $c=c^{*}$ defines the crack length at which the material becomes notch-sensitive [65]. The equation (8) reduces to the Griffith condition when $c>c^{*}$; we then have a "low-stress" failure with $\sigma_{f}<<\sigma_{1}$. When $c<c^{*}$, the fracture stress approaches $\sigma_{1}$, the strength of the layer ahead of the crack. This equation is successful in describing the stresses at which failures occur below general yield in large structures and may be used to estimate dangerous notch sizes in them $[64-66,70,83-85]$. A1so, with $\sigma_{1}$ identified with the ultimate tensile strength or the collapse stress, and with an appropriate stress intensity factor for the geometry considered it is remarkably effective in correlating post yield fractures with defect size in a wide class of materials $[68,69,96]$ and can be used to estimate $K_{1 c}$ values from "invalid" ASTM tests. It has also been suggested as an interpolation between failure by plastic collapse and ineax elastic fracture mechanics, of potential use in assessing critical lefect sizes in large structures and in design [97]. The engineer cannot rord to make mistakes and, if he must, he will test his actual structur 6 destruction. His inclination is frequently for the simplest approach hed on large-scale tests [98]. Although the great simplifications in me value in the correlations which he has nevertheless to make.

the theory gives for the fracture energy $2 \gamma$ the expression $\sigma_{1} \phi_{c}$. We distinguish two modes of fracture [22,61]; a stable, non-cumulative or

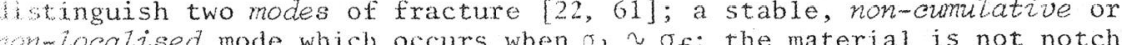
mensitive. The non-linearity represented by the dislocations spreads chrough the specimen much faster than the crack. The second spreads mough ive or localised and is unstable; in this type of failure the aterial is notch-sensitive for $c \geqslant c^{*}$. A similar localised set of discocations representing the non-linearity moves with the crack as it grows, o that it can advance without the non-linearity spreading through the whole net section ahead of it; the fracture is a low-stress one with $\sigma_{1}$ and $c>x$, the extent of the non-1inearity $\left(r \sim \pi c^{*} v E \phi_{c} / \sigma_{1}\right)$. we can see with this classification the mechanical similarity of fractures ith very different values of $2 \gamma^{\prime}=\sigma_{1} \phi_{c}$. Thus ideal brittle fracture, iscontinuous ductile-cleavage, mode I plane stress necking and mode III ductile tearing, and the $45^{\circ}$ shear mode in steel plates are all cumulative. axcept for the first all involve a mechanical instability because the apacity to harden has been exhausted, non-linear flow has concentrated, nd large strains have occurred. These large strains are possible whenver free surfaces allow large geometry changes, on a microscale at bluntimacroscale when the specimen is (relatively) small in one dimension.

\section{MUER CRITERIA}

mumber of other proposals for the characterisation of post-yield fracares have been made, some of which are reviewed at this meeting [52 - 54 , $99-103]$. Their use and applicability are still a matter of active wrent research. However, the concept of the $R$ curve $[100,104-106]$ erhaps deserves special mention. It touches upon the fundamental conlitions for fracture referred to at the begimning of this paper, and also Arcussed in one of the plenary sessions here [107]. The crack will not twa until the it advances. The R-curve gives explicit recognition to the idea that the physical processes for the advance of the crack (cracking and sliding off is combination on a microscale) can occur, but recognises that these processes are, temporarily, self equilibriating. Just as a material work haxdens, so the resistance $\mathrm{R}$ to crack propagation rises. Many workers have considered this phenomenon [10]. Here we wish only to draw attention o the fact that it again forces us to think in detail about the processes of sliding, blunting and microcracking which are going on at the crack tip It all the materials we consider $[107$ - 115$]$. It may well be that we shal heir sensitivity to the strain-rate and the environment.

THER PATH - INDEPENDENT INTEGRALS

Where are other path-independent integrals of use in the theory of fracture thes a ses the $J$ and the $F$, we have already discussed. Before doing so we 
make a few comments on the rather profligate introduction of "new" integrals currently in fashion. This is not the place for the detailed cxitique of individual proposals, but we believe that those planning to launch a vessel of this kind should first study carefully the backgroun theory and bear the following points in mind.

Firsty, a complicated integral expression may be path-independent because, in any example of interest, it is identically zero. Secondly, we have to distinguish two types of path-independence. If the two-dimensional value for two paths each beginning at a point A on the lower crack surface and ending at a point $B$ on the upper crack surface. However the value may be different for a path beginning at another point $A_{1}$ on the lower surface and ending at another point $B_{1}$ on the upper. Indeed it will be unless the sum of the contributions from the paths $A_{2} A$ and $B B_{2}$ is zero. $1 f$ this sum is zero for $a_{11} A_{1}$ and $B_{1}$, then the integral has the same value for all paths beginning at any point on the lower surface and ending at any point on the upper; we can slide the points $A$ and $B$ along the crack faces in any manner without changing its value. It is this kind of path independence which is of real value, since we can deduce values for paths close to the tip from those placed far away at our convenience, where the Field quantities are easier to find. Of course, we can always make an expression "path-independent" by subtracting from it the contributions from the paths $B B_{1}$ and $A_{1} A$. But then, if we wish to use the expression, we still have to evaluate these contributions, and this requires a know-

The general theory of path-independent integrals stems from the work of Noether [116]. They arise for any field when the Lagrangian density function fxom which the field equations are derived is invariant under the general consequences for 作 In addition to Fig he found the integrals

$$
\begin{aligned}
& L_{k \ell}=\int_{S}\left(x_{k} p_{\ell j}-x_{\ell} p_{k j}+u_{k} p_{\ell j}-u_{\ell \ell} p_{k j}\right) d S_{j} \\
& M=\int_{S}\left(x_{\ell} P_{\ell j}-\frac{1}{2} u_{\ell} p_{\ell j}\right) d S_{j}
\end{aligned}
$$

also given by Budiansky and Rice [118]. $\mathrm{F}_{\ell}, L_{\mathrm{k} \ell}$ and $M$ are path indepen dent because a picture of a general elastic field remains one after it has been respectively translated, rotated and enlarged. Consequently $[19,20]$ Fe is valid for finite deformation and a non-linear material, provided only that it is homogeneous, while for $L_{k} \ell$ the material must in addition be isotropic. For $M$ we must have linearity in the displacement gradients, but we may have anisotropy. There are some special cases in which these requirements may be relaxed [9]. Arguments have been given Noether's type and that in plane situations the only new feature is that (10) reduces to

$$
M=\int_{S} x_{\ell} P_{\ell, j} d S_{j}
$$

transformation which results from Gauss's theoren [19]. However, in wo dimensions, several infinite classes of path-independent integrals wave been found [19].

$t$ is interesting to calculate the force $F_{2}$ given by (2). We may think bosely of $\mathrm{F}_{2}$ as the force normal to the crack tip, but its interpretation waires some care. If we evaluate $F_{2}$ using the singular stresses (1): wat is, for a small circuit about the crack tip, we find that $F_{2}=-2 K_{1} K_{2}$ $1120,121]$. This is an example where the integral (2) has a different whe for a large circuit round the crack tip; that is, the integral is not path-independent in the really useful sense because there are, outside the singular field, non-vanishing contributions along the crack faces. we cannot make a useful path-independent integral simply by subtracting the crack face terms [121], because we still have to know the field along the crack if we wish to use such an integral. It is indeed [24] easy to Wow that $F_{2}$ is the limit of $(\pi / 2) p_{11} u_{2}$ as the tip is approached along wher the top or bottom surface of the crack.

coosely, we expect $F_{2}$ to push the crack sideways, and this raises the nteresting question of what determines the path of a crack. This problem tso axises in considering fracture under combined stresses and in crack corking. It is a subtle one because the crack constantly alters the Mold as it proceeds. A possible criterion j.s that the crack moves so as 0 keep $F_{2}=0$ [24]. This has been used by Kalthoff [122] in the form ? 0 to discuss the angle at which a crack forks. See also [123] for of equivalent proposal. There has been considerable interest for some whe both in the "angled-crack" problem and in the more general problem of rack initiation under combined stress and a number of theories have been roposed [124-129]; for a selection of earlier references, see [51]. discussion of these problems based on an analysis $[130]$ of a crack under cnoral loading with a small kink at its tip making an angle $\alpha$ with the ain crack was given at a recent meeting [51], several authors have whlished analyses of this kind $[130$ - 133]. However, to discuss the nset of deviation, or for initiation of the kink under combined stress, he most suitable results are those for the limit when the kink is vanish mo small compared with the main crack. Several criteria for the path initiation have been examined using results of this kind [5], 130 , 531

The integral $L_{k}$ enables an alternative interpretation of the force $\mathrm{F}_{2}$ to given when the crack with a kinked tip is considered. If $f_{1}$ and $f_{2}$

(c)

Lef the kink, then it nay be shown [20] that

$$
f_{2}=\left[\frac{d f_{1}}{d x}\right]_{\alpha=0}
$$

at is, if the tip of the main crack deviates through a small angle da, the change in the crack extension force $f$, is $f, d \alpha$. Several authors have Aso recently examined the problem of the forked crack $[134-135]$; the cesults show some discrepancies [135]. Again, for the initiation of roxing, the case when the forks are vanishingly small is of most interest ffer very much from that observed and calculeted by kalthoff [122]. keference [19] contains the expression fox $P_{\ell, j}$ for a material of grade 2 ;
there seems to be some uncertainty in its application to crack problems 

$[20,136]$. Other examples of the application of path-independent integrals to problems of fracture are also given. They include a discussion of Obreimoff's experiments on mica; of the "trouser test" for rubber using (2) with finite deformation; and of the two-dimensional analogue of the "conical crack", and of the edge crack wedged open by concentrated forces, using (11). The static version of equation (59) of [15] furnishes an integral which is path-independent in the presence of certain types of body forces.

Before leaving the topic of path independent integrals we wish to repeat the brief comment we have made [137] about the use of the quantities $\mathrm{j}$ or $C^{*}$ in creep crack growth; for a selection of references see [138]. If the material is linear, viscous and incompressible and the flow is slow then we can make the usual analogy with linear elasticity by replacing the displacement by the velocity, the shear modulus by the viscosity and by setting Poisson's ratio equal to one half. Then an integral of the form of $F_{1}$ is path-independent. However, what it represents is the following $[20]$. A body instantaneously contains a crack of length a unde some load and a state of viscous flow is established. All the work done by the external forces is being dissipated by the viscosity and there is a certain dissipation rate. Now the crack is lengthened by $\Delta a$; then the elastic-viscous analogy shows that $2 \mathrm{~F}_{1} \Delta \mathrm{a}$ is the increase in the rate of dissipation when the boundary loading is held fixed, but the decrease in it if the boundary velocities are kept constant [24]. In other contexts, this kind of integral can perhaps be used [20] to select from a class of slow viscous flows depending on parameters a flow which is actually observed, by requiring that the dissipation be stat fonary (although the principle involved is not easy to justify). It is not, however, clear how ten lant pared with experiments, but some quantity whe which is usually conpared with experiments, but some quantity which would be the G derived Moreover, the viscosity is non-linear. Nevertheless, if creep crack growth can be satisfactorily characterised in this way, there will clearly be a need for some xe-interpretations.

In fact, one must expect a crack in a linear viscous material to elongate in the direction of the stress [139]. A hole is a special case of an the deformation of ellipsoidal viscous inhomogeneities [140, 141$]$, a process of interest in glass manufacture, geology and in the interpretation of phenomen in inhomogeneous fluids. The growth of voids at crack tips is, of course one of the phenomena we must understand if we are to in prove our model of the processes going on there [142 - 1.46].

MOVING CRACKS

We refer only briefly to moving cracks; for more detailed accounts see $[11,12,15,16,51,147-151]$. In a general dynamic elastic field there is no path-independent integral for the force on a moving crack. The best we can do [12] is to write the elastic field in the form

$$
u_{i}=u_{i}^{0}\left(x_{1}-v t, x_{2}\right)+u_{i}^{\prime}\left(x_{1}, x_{2}, t\right)
$$

and try to arrange that near the tip $u_{i}{ }^{\prime} \ll u_{i}^{0}$. Here the crack tip is aving with instantaneous velocity $v$ in the $x_{1}$ direction. Then we can write

$$
G=\lim _{S \rightarrow 0} \int_{S} H_{\ell j} d S_{j}
$$

where $S$ is a surface moving with the crack tip and

$$
H_{\ell j}=(W+T) \delta_{i j}-p_{i j} u_{i, \ell}
$$

wore $T$ is the kinetic energy density. It should be noted that $H_{\ell} j$, is not the dynamic $4 \times 4$ energy-momentum tensor $\mathrm{Phj}$. The integral of the dynami aives the force on the crack tip, plus the rate of change of "quasi monentum" insides $[15]$.

The integral (14) is, in genexal, path-independent only when $S \rightarrow 0$. If the dynamic elastic field is a special one which moves rigidly with the rack tip, then $G$ is independent of $S$, but special simple fields can be used to show that this independence cannot be true for arbitrary finite in a general dynamic field [12]. It may be shown [12] that G vanishes at the Rayleigh velocity for the uniformly expanding crack in plane stra $1152,153]$, and

The equation of motion may be found by allowing the crack tip to move mitrarily so that at time t. its tip is at $x=\xi_{(}(t)$, say, and then cal abitrarily so that at time t. its tip is at $x=\xi(t)$, say, and then cal157]; Freund [158] has extended the work to plane strain. We can then calculate 6 , which turns out to be a function of $\xi$ and $\xi$, but not of $\xi$; the crack tip behaves as if 1 to had no mex equation of motion $i s$

$$
G(\xi, \dot{\xi})=2 \gamma(\xi, \xi)
$$

We find that the velocity dependences of $G$ and $k$ are different, and that contains a factor which increases as the velocity fails. We can thus whderstand how the conservation of energy can be maintained during crack wisht be set by requiring that the crack momentaxily stops $[15,158]$. with the continuing interest in the solution of dynanic crack problems With the continuing intexest in the solution of dynamic crack probstanding of discontinuous crack propagation, crack paths and crack branching.

\section{1]ISCUSSION}

He have been able to refer to a few only of the many interesting papers this meeting. About specific materials and their behaviour in composites [107] we have said very little. We have not mentioned the effect of the environment $[166-167]$, the phenomenon of fatigue $[168,169]$, or the growth of cracks in creep [170], all topics in the front line of practical interest. Nor have we touched on the efforts now being made to take a more three-dimensional look at the fracture problem, which stretches our analytical and computing powers and also raises some interesting 
topological questions [1.14]. Anong the papers also, there are several references to probability and statistics, applied both to flaws and to microstructure $[108,171\}$ and to failure probabilities $[172,173]$. These methods will be with us increasingly, and the analysis of reliability will we should devote oux current attention.

In cavitation during high temperature creep [174] we have to consider thexmally assisted motion of individual atoms. This provides us with a gentle introduction to the phenomena where nechanics alone will not do and we have to consider the combined effect of stress, strain, temperature and electro-chemical processes. Cracking, sliding and individual atom movements all play their part in contributing to creep damage. Johnson's work [170] reminds us that the damage may be genexal or local and that we may relieve stresses both by sliding, and by void formation and microcracking, a process occurring acro in britele interian of interest to the engineer are that although the macroscopic creep rates of interest to the ongineer are very slow, these rates may be much faster in local regions where stress is concentrated. Thus we must consider a range whole, and warns mation and fallure map [17, helps of the pitfalis associated with the too that as the to be made. These maps remind us too that as the strain rate rises, the problem of creep fracture passes into that of workability [176, 17 behaviour emphasis on mechanism also recald the crystine materials at least, we

may be viscous, in small regions of crich atoms and dislocations are moving have blocks of elastionating.

particularly challenging are those fractures where we have to think of the Pronsport of impurities across internal and external surfaces, as these cransport of impurities across intern [166]. of the migration of these are exposed and the effects produced when they are segregated, adsorbed on impurites and their trapping and precipisurtaces, or associated with dubbes of gas within the solid $[174,178$, cation as chenomena, as of fatigue is also in1791. ln the $[168,169]$ we are led yet again to focus on the detail fuenced by 114 , $115,180-183$ I In trying to characterize the intrinsic ductility 3. - In processes on this scale, the true suip act on modified surface energy which is still quite small) surlace encer widely argued (for example, $[38,39,186]$ ) is Lis the whole macroscopic toughness may be affected. the lare suaster surface energy, important for the microprocesses. Adsorption can make a radical change in the true surface energy (see $[187,188]$, for cxample so that in this way we can explain the effect of trace impurities. cxam molel will not be complete however unless it takes account of the rates at which the various competing processes occur. Despite the prexecosation with macroscopic toughness, the critical experiments and the interpretation necessaxy to formulate such a rate-sensitive model of these crack tip processes must be continued.

The subject of fracture embraces the full range of the study of condensed matter; it is necessary both to test large engineering structures, and to use the most refined techniques for detecting the presence of individua atorns. We have to consider the deformation and flow of many types of
The work touches on earthquakes and the failure of rocks and masses of ice $[189]$; on the integrity of pressure vesse1s, pipelines, aircraft and electrical generators; and on the structure ar our very selves [190]. There are many interesting phenomena to be investigated and some formid at an interesting meeting.

\section{ACKNOWLEDGEMENTS}

am greatly indebted to Professor J. D. Eshelby, Dr. I. C. Howard and Mr. G. E. Cardew for many valuable discussions.

REFERENCES

1. BILBY, B. A. and ESHELBY, J. D., In: "Fracture", (ed. H. Liebowitz), . $1968,99$.

2. IRWIN, G. R., In: "Fracturing of Metals", ASW,

3. IRWIN, G. R., J. App1. Mech, 24, 1957, 361.

4. IRWIN, G. R., Handbuch der Physik, VI, 1958, 551.

5. GRIFFITH, A. A., Phil. Trans. Roy. Soc., A221, 1920, 103.

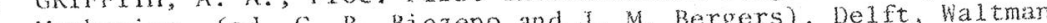
$1924,55$.

7. ESHELPY 30

8. SANDERS, J. L., J. App1. Mech., 27, 1960, 352

9. RICE, J. R., J. App1. Mech., J5, 1968, New York, if 1968,191

1. Cur

11. Chetror

12. ATKINSON,

13. Caklin) un

. Thelastic Behaviour of Solids", (ed. M. F.

. Kantinen et al, MCGraw Hill, New York, 1970, 77.

6. BI B B A. In: "Amorphous Materials", Proceedings of the Third Interational Conference on the Physies of Non-Crystanme Solids, Sheffield (ed. R.W. Douglas and B. Filis), Wiley, New York, 1972, 489 .

17. ESHELBY, J. D., In: "Internal Stresses and Fatigue in Metals", (ed. R. M. Rassweiler and W. L. (Grube), Elsevier, Amsterdam, 1959, 41.

R. M. Rassweiler and W Late Physics, 3, 1956, 79

19. ESHELBY, J D In: "Prospects of Fracture Mechanics", (ed. G. C. Sih

.

20. ESHELBY, J. D., Journal of Elasticity, 5, 1975, 321.

21. BILBY, B. A., Advanced Seminar on Fracture Mechanics, Commission of
the European Comnunities, Ispra 1975, Paper ASFM/75, No. 6. BILBY, B. A., Papers presented to the Third Internationa on Fracture, Munich, Part XI, 1973, 1. 1973. see [22].

23. HOWARD, I. C., Private communication, 1973 :

24. ESHELBY, J. D., Private communication, 1974 .

25. HUTCHINSON, J. W., Report DEAP S-8, Division

26. Applied Physics, Harvard University, Journal Fract., 11, 1975, 349.

27. RICE, J. R, int. Journal pract., 11, 1975, 352. 
28. NEALE, B. K., CEGB Report. No. RD/B3253, 1975

29. ROCHE, R. L., "Fracture 1977", (ed. D. M. R. Taplin), University of Waterloo Press, Canada, $11,1977$.

30. BILBY, B. A. and ESHELBY, I. D., Unpublished work.

31. BILBX, B. A., Progr. Solid Mech., 1, 1960, 331.

32. BILBY, B. A., IUTAM Symposium Freudenstadt-Stuttgart, Mechanics of Generalized Continua, (ed. E. Kroner), Springer, 1968, 180.

33. KRÖNER, E., "Kontinuumstheorie der Versetzungen und Eigenspannungen", Springer, 1958

34. HULT, J. A. H. and MCCLINTOCK, F. A., Proceedings of the Ninth International Congress on Applied Mechanics, 8, 1957, 51

35. SWINDEN, K. M., Mh. A. Thesis, University of Sheffield, 1964

YOKOBORI, $\mathrm{T}_{0}$ and ICHIKAWA, M., Reports of the Research Institute for Strength and Fracture of Materials, Tohoku University, Sendai, 2 , 1966,21

37. ATKINSON, C., Ark. Fys., 35, 1967, 469.

- RICE, J. R., Proceedings First International Congress on Fracture Sendai, (ed. T. Yokobori et al.), Jap. Soc. Strength and Fracture of Materials, Tokyo, 1, 1966, Papex A-18, 309

39. RlCE, . . and DRUCKER, D. C., Int. Journal Fract., 3, 1967, 19. KFOURI, A, P. and MLLLER, K. J., Int. J. Pres. ves. and Piping, 2 ,

41. KrOURI, A. P. and MILLER, K. J., "Crack Sepaxation Energy Rates in Elastic Plastic Fracture Mechanics", to be published in Proc. Inst. Mech. Eng. (London).

2. KFour, A. P. and RICE, J. R., "Fractuxe 1977", (ed. D. M. R. Taplin), University of Water100 Press, Canada, I, 197 t.

43. KFourl, A, P. and MILLER, K. J., "Fracture 1977", (ed, D. M. R. Taplin), University of waterloo Press, Canada, IT, 1977.

44. OROWAN, E., Reports on Progx. in Physics, 12, 1949, 214

45. Cherepanov, G. P., Prikl. Mat. Mech., 33, 1968, No. 3.

46. WNUK, M. P., Int. Journal Fract. Mech., 7, $1971,217$.

Mech. 1973,1

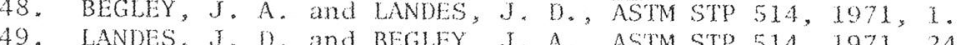

BUCCI, R.J PARIS, P. C. LANDES, J D and RICE, J R. ASTM STT

$514,1971,40$.

1. BILBX, B. A., Conference on Mechanics and Physics of Fracture, Cambridge, Jamuary $1975,1 / 1-1 / 11$.

52. RICE, J. R., PARIS, P. C. and MERKLE, J. G., ASTM STP 536, 1973,231

53. ADAMS, N. J. I. and MUNRO, H. G., Engng Fract. Mech., 6, 1974, 119.

54. BEGLEY, J. A. and LANDES, J. D., ASTM STP 536, 1973, 246.

55. CoTtreli, A. H., Symposium on Steels for Reactor Pressure circuits, 1960, Special Report No, 69 , I S I London, 1061 , 281 .

56. BILBY, B. A, COTTRELI, A. H. and SWINDEN, K. H. Proc. Roy. Soc. A272, 1963,304

57. DUGDALE, D. S., Sommal Mech. Phys, Solids, 8, 1960, 100.

58. Barkinblatt, G. I., Prik1. Mat. Mech., 23, 1959, 434,706,893; Advan.

59. VITVITSKII, P. M. PASYUK, V.V. and YAREMA, S. Ya., Engng. Fract. Mech., 7, 1975,305

60. PRANDTL, L., Z. f. angew, Math. und Mech., 13, 1933, 129

61. COTRRELL, A. H., In: "Properties of Reactor Materials and the Effects of Radiation Damage", (ed. D. I. Littler), Butterworths, London, 1962,5 .

62. COTTRELL, A. H, Proc, Roy. Soc, A276, 1963, 1.

63. COTTRELL, A. H., Proc, Roy. Soc, A282, 1964, 2.

64. Cortrell, A. H., Proc, Roy. Soc., A285, 1965, 10.
65. COTTRELL, A. H., In: "Fracture", Proceedings of the first Tewkesbury Symposium, 1963 (ed. C. J. Osborn), Butterworths, London, 1965, 1. Roy. Soc., A272, $1963,304$.

67. SMITH, E., In: Proceedings of the First International Congress on Fracture, Sendai (ed. T. Yokobori et al.), Japanese Society for

68. HEALD, P. T. SPINK, G. M. and WORTHINGTON, P. J., Mat. Sci. Engng. $10,1972,129$

69. WORTHINGTON, P. J., SPINK, G. M. and HEALD, P. T., In: Proceedings of the Third International Congress on Fracture, Munich, IX, 1973, Paper 515 .

70. BlLBY, B. A. and SWINDEN, K. H., Proc. Roy. Soc., A285, 1965, 22.

71. ATKINSON, C. and KAY, T. R., Acta Met., 19, 1971, 679.

72. ATKINSON, C. and CLEMENTS, D. L., Acta Met., 21, $1973,55$.

73. SMITH, E., Proc. Roy. Soc., A299, 1967, 455.

74. SMITI, E., Int. J. Engng Sci., 5, 1967, 791 .

75. BHAB, B. A. and HEALD, P. T., Proc. Roy. Soc., A305, 1968, 429

76. HEALD, P. T, and BLLBY, B. A., In: "Fracture Toughness of High

Strength Materials", TSl Publication No. 120 , 1968, 03.

WEERTMAN, J., Int. Joumal Fract. Mech., 2, 1966, 460.

7. WEERMAN, J., hnt. Journal Fract. Mech., $5,1969,13$.

79. FLEWITT, P. E. J. and HEALD, P. T., In: "Fracture Toughness of High Strength Materials", IST Publication No. 120, 1968, 66.

Kostrov, B. V. and NIKITTN, L...., PfikT. Mat. Mokh., 31, 1967, 334

1. ARTHUR, P. F. and BLACKBURN, W. S., In: "Fracture Toughness of High

82. HOWARD, I. C. and OTTER, N. R., J. Mech. Phys. Solids, 23, 1975, 139

. SMTTH, E., Froc. Roy. SOc., A285, 1965, 46.

84. HAXES, D. J. and WILLIAMS, J. G., Int. Journal Fract. Mech., 8, 1972, 239

85. FENNER, D. N., fint. Joumal Fract., 10, 1974, 71. 86. CHELL, G. C., Int. Journal Fract., 10, 1974, 128

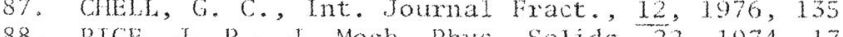

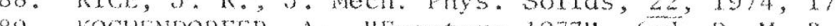

Kodwaplin), University

90. RLEDLL, K., Jouxnad Mech. Phys. Solids, 24, 1976, 277.

91. WITEK, V. Joumal Wech. Phys Solids, 24, 1976, 263.

92. WELLS, A. A., Proceedings of the Crack Propagation symposium, Cranfield, 1, 1961, 201 .

93. WELLS, A. A.', Brit, Welding Journal, $12,1965,1$

94. BURDEKIN, F. M., STONE, D. E. W. and WELLS, A. A., In: "Fracture Toughness Testing, ASTM STP $381,1965,400$.

95. EGAN, G. R., Eng. Fract. Mech., 5, $1973,167$.

96. HEALD, $\mathrm{P}$. T, and EDMONSON, B. "In: "Periodic Inspection of pressurized Components", Institution of Mechanical Engin-ers, London, 1974

97. DOWLING, A. R. and TOWNLEY, C. H. A., Int. J. pres. Ves. and piping, $3,1975,77$

98. SOETE, W., "Fracture 1977", (ed. D. M. R. Taplin), University of Water1oo Press, Canada, I, 1977.

99. LIEBOWTTZ, H., EFTIS, J. and JONES, D. L., "Fracture 1977", (ed. D. M. R. Taplin), University of watertoo press, Camada, , 1977 .

100. TRWIN, G. R. and PARIS, P. C., "Fracture 1977", (ed. D. $\bar{M}$. R. Taplin), University of Waterloo Press, Canada, I, 1977

101. WITT, F. J. and MAGER, J. R., Nuc1. Eng. Design, 17, 1971, 91 ,

102. ÖSTENSSON, B., Eng. Fract. Mech., 6, 1974, 473. 
103. MERKLE, J. G., ASTM STP 536, 1973, 264

. 6., AStM St86, S Naval Research Lab. 1960

105. JW KRAm , J

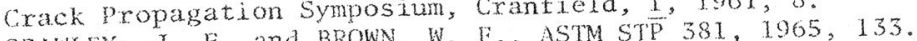

106. SRAWLA, J. Le PlGGOTT, M R, "Fracture 1977", (ed. D. M. R.

107. COOPER, 6. A. and PICH, Whe 1977.

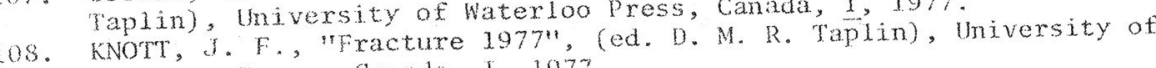

109 Nator Rice, J. R. and Jocraw Hi11, New York, 1970, 511.

110.

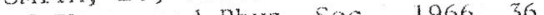

1. of Phys and thys Soc. J. F, and RICA, J. R., J. Mech. phys. Solids Ri.

12. COMLNG M. J and HANCOCK, J. W., "fracture 1977", (ed. D. M. R Concin), University of Waterloo Press, Canada, 11, 1977.

13. HaNcock, J.W. and Cowling, M. J., "Fracture 1977", Ced.

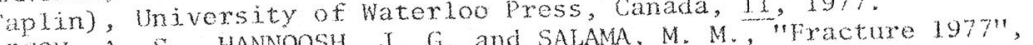

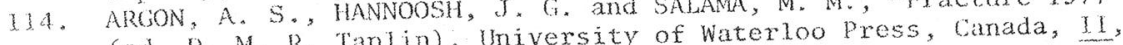
(ed.

15. EVANS, A. G., Hever, A. H. and Porter, D. L., "Fracture 1977", (ed 13. $\mathrm{R}$. Taplin), University of Waterloo Press, Canada, $1,1977$. B. Möt Sransport Theory and Stati(English txanslation by M.

Cijte W. Abh bxaunsch. wisch. Ges., 14, 1962, 54

, Dech. 40, 1973, 201.

118. BUDLANSKY, $B$, and RICE, B. R., A., Arch. rat. Mech. Anal., 44, 1972, Kow.

187. a Noordhoff International, Leyden

121. Bercez, D., Revue de Phys. Appliquée, $276,1973,1425$. KALTHOF, 3., Proc.

A. 1075, Paper S25. and SALGANIK, R, L., Int. Soumal Fract. 10, 1974 ,

507. M. C. and KOMANDUR, R., "Rracture 1977", (ed. D. M. R. Tuplin), Shiversity of Wordoo press, Canada, IT, 1977. PISARBNKO, G. S. and LEBEDrev, A. A., Canada, $11,1977$.

Taplin), University of Waterloo Press, R. Taplin), University of MAREK, P., "Fracture 1977", (ed.

Water100 Pxess, Canada, M, 1977. and PRASAD, $\mathrm{s}$. V., "Fracture 1977",

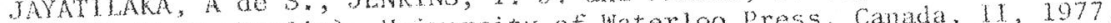
(cd. D. M. R. Taplin), University bef

128. HAN, G. I., HOAGLAN, K. G. and of (ed. D. M. R. Tapin) o University or Waterio 1977", (ed. D. M. R.

129. KIRCHNER, $11 . P$. and GRUNLR, R. M , w Taplin, , University of Waterioo p, $11,1975,708$. BILBY, B. A., and CARBW, G. B., Tnt Jounal Journal Fract. $8,1972,114$.

31. PALANYSWAMY, $k$. and KNAU,

132. COUGHLAN, J. and BARR, B. 1. O., Solids Struct., 11, 1975, 521.

133. CHATTERJEE, S. N., Tht. JoMnal solj.ds String Fxact. Mech., 7, 1975,

134. KITTGN

521. KITAGAWA, H. and $y$ 13ab. CHEREPANOV, G. P. and KULTEV, V. D., Int. Journal Fract., 11, 1975, 29.

134c. THEOCARIS, P. S. and roAkImidis, N., J. Appl. Math. and Phys., 27, 1976,801

T., Ph.D. Thesis, university of California, 1975

$134 \mathrm{e}$ HUSSAIN, M. A., PU, S L and UNIERWOOD, I., ASTM STP 560, 1973, 2 ; 150, Craduate Aeronautical Laboratories, California Institute of Technology, Report No 74-8, to appear in Mechanics Today (ed. S. Nemat-Nassex), Pergamon.

134f. VITEK, V., "plane Strain Stress Intensity Factors for Branched Cracks", CEGB Report No, RD/L/N210/76.

135. BILBY, B. A., CARDEW, G. E. and HOWARD, I. C., "Fracture 1977", ced D. M. R. Taplin), University of Waterloo Press, Canada, II, 1977. ATKINSON, C and LEPPINGTON, F. G., Int. Journal Fract., 10, 1974 599.

137. BILBY, B. A., Conference on Creep Crack Growth, Sheffield, The Metals Society, Jamuary 1976, unpublished.

138. NEKBIN, K. M. WEBSTER, G. A. and TURNER, C. E., "Fracture 1977", (ed. D. M. R. Taplin), University of Water100 Press, Canada, II, 1977. BERG, C. A., proc. Fourth U.S. National Congress of Appl. Mechanics, Bexkeley, (ed. R. M. Rosenberg), ASME, 2, 1962, 885

140. BILBY, B. A. ESHELBY, J. D. and KUNDU, A. K., Tectonophysics, 28 , 1975,205 .

141. BILBY, B. A, and KOLBUSZEWSKI, M. 1., Proc. Roy. Soc., 1977, to be published.

142. MCCLINTOCK, F. A., J. Appl. Mech., 35, 1968, 56s. Solids, 24, 1976 147 .

144. RICE, J. R. and TRACEY, D. M., J. Mech. Phys. Solids, 17, 1969, 201.

145. NAGPAL. V. MCCLINTOCK, F. A., BerG, C. A. and SUBOH, M. "Foundations of plasticity", International sympositum, Warsaw, 1972 (ed. A. Sawczuk), Noordhote, leyden, 565.

46. PERRA, M. and FINNIR, I., "Fracture 1977", (ed. D. M. R. Taplin), University of waterloo press, Canada, 11,1977

147. Advanced sems nar on Fracture Mechanjes, Commission of the European Communities, Ispra, 1975. Papers by IRWIN, G. R. (AskM/10 and 13), GROSS, D. (ASFM/11), TURNER, C. E. (ASFM/12) and KERKHOF, F. (ASFM/18)

148. BARENBLATT, G. I., ENTOV, V. M. and SALGANIK, R. L., In: "Inelastio Behaviour of Solids", (ed. M. F. Kaminen et al.), McGraw-Hill, 1970,635

149. ATKINSON, $\mathrm{C}$, and WLLLAMS, M. I., Int. Joumal solids struct., 9 1973,237

150. ROSE, L. R. F., Int. Journal Fract. 12, 1976, 799,

51. WTLLIAMS, J G and DEROH, W "Eracture 1977", (ed. D. M. R. Taplin), BROBYRG, K B Ark tiy $18,1960,159$.

53. BROBBERG, K. B., Ark. Fys. $18,1960,159 ., 546$

154. BUSTWICK, A. Sc.(Tech.) Dissertation, Sheffield, 1968

155. Kostrov, B. V., Prikl. Wat. Mekh., 30, 1966, 1042.

156. ESHELBY, J. D., J. Mech. Phys, Solids, 17, 1969 , 177, .

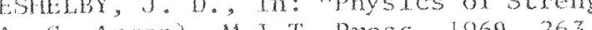

158. Fround, L. B. J. Mech. Phys. Solids, 20, 1972, 129,141; J. Mech.

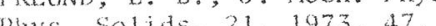

159. ROSE, L.R. R. Pxoc. Roy. Soc. A349, $1976,497$.

160. Wore

161. Not 183 
162. ACHENBACH, J. D., "Fracture 1977", (ed, D. M. R. Taplin), University of Waterloo Press, Canada, II, 1977.

163. ACHENBACH, J. D. and VARATHARAJULU, V. K., Quart. App1. Math., 32, $1974,123$.

164. FREUND, L. B., Int. Journal Engng. Science, 12, 1974, 179.

165. ROSE, L. R. F., Int. Journal Fract., 12, 1976, 829.

166 SCULLY, J. C., "Fracture 1977", (ed. D. M. R. Taplin), University of Waterloo Press, Canada, 1 I, 1977.

166a. MCMAHON, C. J. Jr., BRIANT, C. L. and BANERJI, S. K., "Fracture 1977", (ed. D. M. R. Taplin), University of Waterloo Press, Canada, I., 1977.

167. KAMDAR, H. H., "Fracture 1977", (ed. D. M. R. Taplin), University of

168. Coffin, L. F., "Fracture 1977", (ed. D. M. R. Taplin), University of Waterloo Press, Canada, I, 1977

169. BEEverS, C. J., "Fracture 1977", (ed. D. M. R. Taplin), University Water Canada, I, 1977.

170. MCLEAN, D., DYSON, B. F. and TAPLIN, D. M. R., "Fracture 1977", (D. M. R. Taplin), University of Waterloo Press, Canada, I, 1977. "Fracture 1977", (ed. D. M. R. Taplin), University of Waterloo Press, Canada, II, 1977. Taplin), University of Waterloo Press, Canada, I, 1977.

Taplin), University of Watcrloo press, Canada, 1, 1977.

D. M R Taplin), University of Waterloo Press, Canada, I 1977.

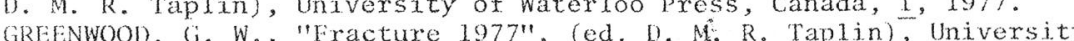
of Waterloo Press, Canada, I, 1977.

D. M. R. Taplin\}, University of Waterloo Press, Canada, I, 1977.

176. KUHAN, H. A. and DIETER, G. A., "Fracture 1977", (ed. D. M. R. Taplin), University of Waterloo Press, Canada, I, 1977.

177. EMbury J, D. and LeROY, (3. H, "Fracture 1977", (ed. D. M. R. Taplin), University of waterloo Press, Caniada, I 1977.

178. GOODS, S. H. and NIX, W. D., "Fracture 1977", (ed. D. M. R. Taplin), University of Waterloo press, Canada, II, 1977 .

179. ALLEN-BOOTH, D. M. ATKINSON, C. and BILBY, B. A., Acta Met., 23,

180. YOKOBORI, T., KONOSU, S. and YOKOBORI, A. T., "Practure 1977", ced. D. M. R. Taplin), University of Waterloo Press, Canada, I, 1977. SMITH, E., COOK, T. S. and RAU, C. A., "Fracture 1977", (ed. D. M. R. Taplin, University of Waterloo Press, Canada, I, 1977. KausCH, H. H., "Fracture 1977", (ed. D. M. R. Tapiin), University of

183. PETERLIN, A., "Fracture 1977", (ed. D. M. R. Taplin), University of Water100 Press, Canada, I, 1977

184. KELLY, A., TYSON, W. and COTTRELL, A. H., Phil. Mag., 15, 1967, 567.

185. RICE, J. R. and THOMSON, R., Phil. Mag., 29, 1974, 73.

186. WILLIAMS, M. L., Int. Journal Fract. Mech., 1, 1965, 292.

187. PETCH, N. J. and STABLES, P., Nature, 169, 1952, 842

188. PETCH, N. J., Phil. Mag., $\frac{1}{7}, 1956,331$.

D. M. R. Taplin\}, University of Waterloo Press, Canada, II, 1977.

190. PIEKARSKI, K. R., "Fracture 1977", (ed. D. M. R. Taplin), University of Waterloo Press, Canada, I, 1977. 